|||||||||||||||||||||

特 集 カオス理論と光の応用

|||||||||||||||||||

\title{
カオスと経済
}

\section{寺崎 健*}

\section{1. はじめに}

経済学におけるカオス的視点からの研究は，こ こ10 年ほどの間に進められてきた。研究内容は, マクロ経済における研究とファイナンス分野にお ける研究の二つに大別される，前者は経済変量間 の非線形微分方程式や差分方程式に基づいて解の 挙動やありうる状態を分析する理論的な研究, 後 者は時系列デー夕に基づいてそこにカオス性が存 在するのか否かを検討する実証分析的な研究が中 心となっている．前者の代表的な研究としては, R. M. Goodwin の非線形景気循環論などがある が [1-5], 本稿では, 後者について, 株価や為替な ど金融市場における時系列デー夕を対象とした研 究を紹介する。

株価変動は, その変動の分布に正規分布を仮定 した幾何ブラウン運動(geometric Brownian motion)にしたがうものとして扱われることが多 い[6,7].しかし，株価变動の分布は，罒 1 に示し たように正規分布と比べて中央が突出しており， かつ，その裾野が厚い(fat tail)という特徴があ る.

これは通常の正規分布にしたがう誤差変動など と比べて, 株価变動の場合, 一般的には非常に小 さな変動を繰り返すことが多いが，希に非常に大

+ Chaos and Economics

* Takeshi TERASAKI

株式会社 野村総合研究所 技術研究開発部

Information Technology Research Lab., Nomura Research Institute, Ltd.
きく上昇したり，下降したりすることもあること を示している。

さらに，このような分布特性は，時間間隔を日 次変動, 月次変動，あるいは年次変動などと変え ても維持され，そこにある種の自己相似性がみら れることが Mandelbrotによって指摘された[8].

このような分布が生ずる理由として，いくつか のメカニズムを考えることができる，その一つと して，株価変動が正規分布とは異なる安定分布に したがっているのではないかという考え方がある。 正規分布にしたがう確率変数の和はやはり正規分 布にしたがうが，このような性質をもった分布で 正規分布以外のものを想定しょうという訳である。 この見解は Mandelbrotにより主張されたもので あるが，現在では後でも述べるように独立同一分 布にしたがうという仮説はほぼ否定されている $[9]$.

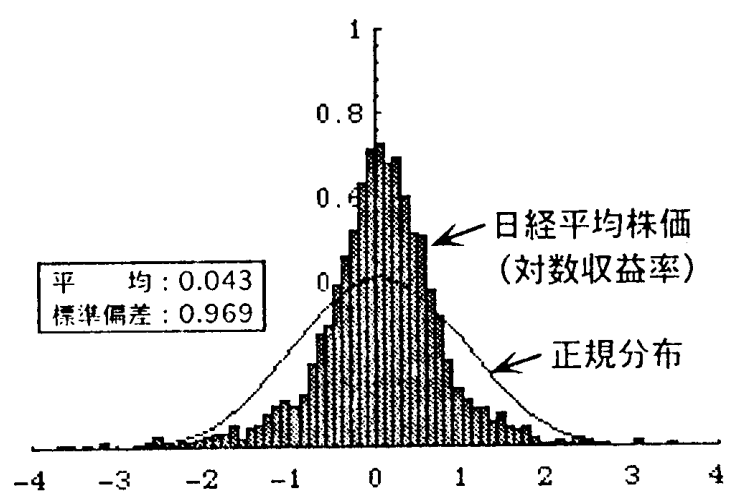

図1日経平均株価の日次対数収益率の分布 (1980年1月初～1990年12月末） 
それでは，市場がカオス力学系にしたがってい るのではないかという仮説を立てた場合にはどう であろうか. その場合，一見ランダムに見えなが らこのような大きな変化を生ずるような事象をう まく説明することができ，バブルだとか金融恐慌 だとかも，そこから説明がつくのではないかと期 待できる。

さらに，実際のデータがカオス性を有していれ ば，それを規定している力学系を推定することに より, 精度のよい短期予測も可能になる。

また，カオス力学系の軌道は二度と同じ道を通 らないので，歴史的な発展過程としての経済時系 列を説明するのに都合がよいという点もある。

このように，ファイナンスにおいてカオスは非 常に魅力的な対象であるが，果たして実際のデー タはカオス性を示すのであろうか.

\section{2. 経済時系列のカオス性解析}

カオスの特徵としては, 自己相似性, 軌道不安 定性，長期予測不能性などがあげられる $[10,11]$ 。 以下，経済時系列デー夕を対象にして，これらの 各性質に関する分析の現状を見ていくことにする.

\subsection{Takens の埋込み定理}

時系列データのカオス性解析には, 次の Takens の埋込み定理 $[12,13]$ が基本となる.

Takens の埋込み定理 $M^{n}$ を $n$ 次元のコンパク 卜な多様体, $f: M^{n} \rightarrow M^{n}, g: M^{n} \rightarrow R$ を $C^{2}$ 級写 像とするとき， $m \geqq 2 n+1$ であれば，

$$
\begin{aligned}
h(x)= & \left(g(x), g(f(x)), \quad g\left(f^{2}(x)\right), \cdots,\right. \\
& \left.g\left(f^{m-1}(x)\right)\right)
\end{aligned}
$$

で定義される写像 $h: M^{n} \rightarrow R^{m}$ は一般的に埋込 みである。

たとえば， $\left\{x_{t}\right\}$ を $n$ 次元の決定論的力学系にし たがって生成される $n$ 次元べクトルの時系列と
し，それを $g: x_{t} \rightarrow \xi_{t}$ なる写像を通して 1 次元の 時系列デー夕 $\left\{\xi_{t}\right\}$ として観測しているものとする. このとき, $\tau$ を時間遅れとして, 次のような $m$ 次 元のベクトルを作成する.

$$
\begin{aligned}
& X_{1}=\left(\xi_{1}, \xi_{1+\tau}, \cdots, \xi_{1+(m-1) \tau}\right) \\
& X_{2}=\left(\xi_{2}, \xi_{2+\tau}, \cdots, \xi_{2+(m-1) \tau}\right) \\
& \text { ・ } \\
& X_{t}=\left(\xi_{t}, \xi_{t+\tau}, \cdots, \xi_{t+(m-1) \tau}\right) \\
& \text {. }
\end{aligned}
$$

このときここの定理によれば, $m$ が $2 n+1$ 以上 であれば上記のように再構成された空間に，元の 力学系のアトラクタの構造が保存されるというわ けである。

一般に観測される経済時系列デー夕は，様々な 経済活動の結果が反映されたものである。したが って，そのデータの背後に非常に多くの要因を考 える必要があるのであるが，この定理は，もし決 定論的な力学系にしたがっているならば，それに 関連する 1 次元の観測デー夕から，その構造が把 握できることを示している。いわば一を聞いて十 を知ることが出来ることを保証した定理であり， 非常に興味深い内容を含んでいる。

なお，経済時系列デー夕には一般にノイズが含 まれることが多いが，ノイズを含んだ場合へと埋 込み定理を拡張する研究も行われている $[14]$.

\section{2 次元解析}

経済時系列がもしカオス力学系にしたがってい るならば，そのアトラクタは自己相似的なフラク タル構造をしているはずであり，その構造は先に 述べた Takens の埋込み定理によって 1 次元の時 系列データから再構成できるので，その次元解析 を行うことによりそれを確かめることができる.

次元解析の手法としては, Grassberger と Procaccia が開発したフラクタル次元の一つの尺 度である相関次元を求める手法がよく用いられる [15]. 相関次元は, 1 次元の時系列デー夕を $n$ 次元 
空間に埋め込んで得られた点を $X_{i}(i=1,2, \cdots$, $N)$ としたとき，次式で定義される相関積分 (correlation integral)を用いて定義される.

$C_{n}(\varepsilon)=\lim _{N \rightarrow \infty} 2 \sum_{i<j} I_{\varepsilon}\left(X_{i}-X_{j}\right) / N(N-1)$ ただし，

$$
\begin{aligned}
I_{\varepsilon}(x) & =1 & & (\|x\|<\varepsilon \text { のとき }) \\
& =0 & & (\|x\| \geqq \varepsilon \text { のとき })
\end{aligned}
$$

時系列データが全くランダムな場合には，埋込 み次元 $n$ を上げていっても埋め込まれた点の集 合は空間全体に一様に分布するだけである。これ に対し，点がアトラク夕を中に偏って分布し， 自己相似的なアトラク夕を形成している場合には， ある指数 $d(n)$ を用いて，

$$
C_{n}(\varepsilon) \propto \varepsilon^{d(n)}
$$

と表現できる，そして，埋込み次元 $n$ を大きくす るにしたがい $d(n)$ はある一定の值 $D$ に収束す る. この值 $D$ を相関次元と呼んでいる.

相関次元解析は最もポピュラーな手法として, いろいろな時系列データに対して適用されてきた。 経済時系列データも例外ではなく, 株価, 為替レ 一ト, GNPなど，ファイナンスばかりでなくマク 口経済デー夕も対象とされ，相関次元が一桁の数 值として求められたという研究結果も提出されて いる $[16-18]$.

しかし, 経済データの場合, 自然科学と異なり 利用できるデータ数が限られているため，相関次 元解析には注意が必要である。この点に関して, たとえばD. Ruelle は, データ数が $N$ の場合, 相 関次元の推定値が $2 \log _{10} N$ より十分低くない限 り信用すべきでないと指摘している $[13,19]$.

日経平均株価や円ドル為替レートの (daily あ るいは tick by tickの) 時系列デー夕に関する筆 者らの分析では, 少なくとも一桁程度の低次元で はないという結果が得られている[20].

\section{3 リアプノフスペクトラル解析}

カオスの別の特徴の一つである軌道不安定性に ついてはどうであろうか。これはリアプノフスぺ クトラム解析によって分析することができる。こ
の分析から得られるリアプノフ指数は，ある時点 での軌道の位置の差が時間的にどのように変化し ていくのかを表す指標であり，特に最大リアプノ フ指数が正であるならば，一般に軌道不安定性を 有することになる $[11,13]$ 。

図 2 は日経平均株価の日次対数収益率に関して, 各埋込み次元別にリアプノフスペクトラムを求め, これをプロットしたものである $[20,21]$.

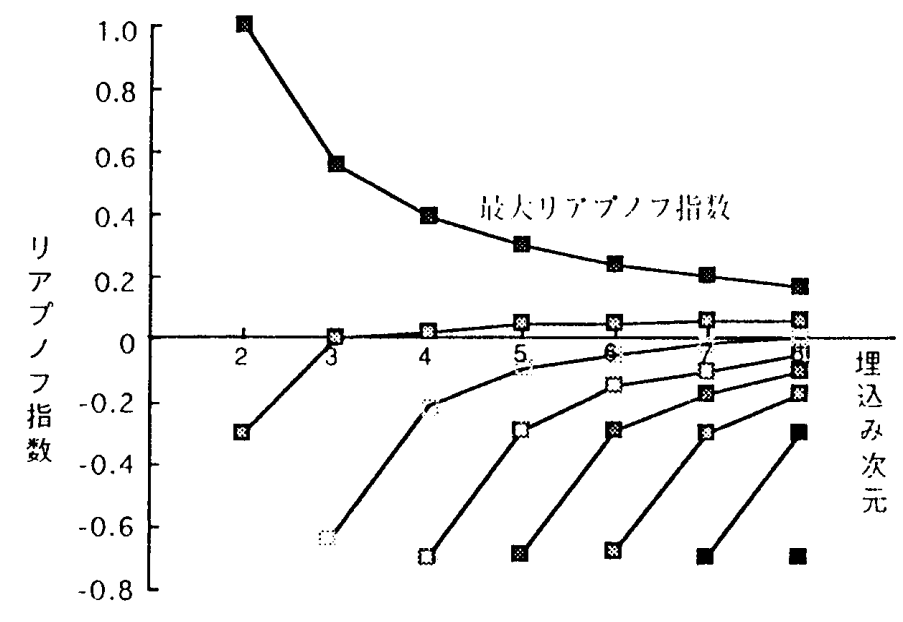

図2日経平均株価の日次対数収益率の リアプノフスペクトラル解析結果 （1976年1月～1992年9月末)

なお，リアプノフスペクトラムの算出方法とし ては，佐野らによるヤコビ行列推定法をべースと したものを用いている[13,20,22].

この図から最大リアプノフ指数が正であること， 埋込み次元を上げていった場合にも，このことは 依然として成り立つであろうことが読みとれる。

円ドル為替レートなど他の経済時系列データに ついても同様の結果が得られており [20]，これら の結果は，経済時系列データがカオス性をもつの ではないかという有力な証拠の一つとなる。

しかし，株価や為替などの最大リアプノフ指数 が負として推定されたとの J. C. Vassilicos らに よる報告もある $[23]$ 。この違いが，分析対象とし たデータの違いに起因するものなのか，あるいは 用いているアルゴリズム(彼らは Wolf らのアル ゴリズム[24]を用いている)等の手法の違いに起 因するものなのか，さらに検討が必要であるよう に思われる。 


\section{4 決定論的非線形予測}

カオスのもう一つの特徴として長期予測不可能 性がある.これを見るには, 1 次元の時系列デー夕 から埋込みによって再構成されたべクトルの系列 $\left\{X_{t}\right\}$ に対して，

$$
F: X_{t} \rightarrow X_{t+1}
$$

なる関数 $F$ が存在すると仮定し，その関数 $F$ を データから推定し，それに基づく非線形予測の結 果を分析するという方法がある [25].

もし，対象とする系が決定論的力学系にしたが っており，かつカオス性を有しているならば，こ のようにして予測された結果は，力オスの長期予 測不可能性を反映し，短期予測では良好な結果が 得られるものの予測時点が先になるほど予測精度 が落ちていくはずである。

関数近似の手法としては，ニューラルネットワ ークの学習アルゴリズムとしてょく用いられる誤 差逆伝播アルゴリズム (backpropagation algorithm), ヤコビ行列推定法[13,22], テセレーショ ン法[26]などいろいろな力法が考えられる.

金融時系列にこの手法を適用したところ，日経 平均株価，川ドル為替レートのいずれの場合でも 生データの場合には, 予測結果は実績デー夕に対 して非常に高い相関が得られたものの，変化分や (対数) 収益率，ボラティリティ(収益率の標準偏 差)などに関する予測では, 殆ど見るべき結果が得 られていない[20].

これは，金融時系列が決定論的力学系にしたが つていないことを示しているのかも知れない。あ るいは，決定論的力学系にしたがっているのだが， その次元が高いため, 高々 10 次元程度までの埋込 みでは対象とする系が十分表現できない可能性も ある。

対象とする系が高次元カオスである場合には, デー夕数が限られているため多くの困難が生ずる. このような場合に有効な方法として，遺伝的アル ゴリズムを利用した局所予測 (local forecasting) と呼ばれる手法が T. P. Meyer と N. H. Packard によって提案されている[27]。このような手法の
経済時系列データへの適用とその有効性の確認は 今後の課題である。

\section{3. 経済時系列の礁率モデル}

経済時系列が決定論的力学系にしたがっている のではないかとの考えは，一見ランダムに見える データの変動の裹側に何らかの決定論的メカニズ ムがあるのではないかという問題意識に基づいて いた。

しかし，以上見たように金融時系列を対象とし た場合には，カオス性を積極的に肯定する結果が 比較的少なく, 少なくとも低次元の決定論的力学 系にしたがう典型的なカオスではないようである。 それでは，ランダムウォークなどの確率過程によ る見方はどうであろうか。

\section{1 ランダムウォーク仮説}

株価変動に関しては，従来から一般的に理論家 には，ランダムウォーク仮説が支持されており， その変動は全くランダムに起こるので，過去のデ 一夕に基づいて予測しようとする行為そのものが 無意味であると信じられている $[28,29]$.

この考えは，通常ブラウン運動を用いて記述さ れる。なお，ブラウン運動とは数学的には次のよ うな条件を満たす確摔過程 $\left\{W_{t}\right\}$ として定義され る.

（1）増分 $\left[W_{t+s}-W_{s}\right]$ は正規分布 $N\left(0, \sigma^{2} t\right)$ にし たがっている

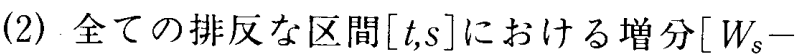
$\left.W_{t}\right]$ は独立

（3） $W_{t}$ は $t=0$ において連続

特に， $\sigma=1$ の場合を標準ブラウン運動と呼ぶ. 株価変動は, $\left\{W_{t}\right\}$ を標準ブラウン運動とし, 時 点 $t$ での株価を $S_{t}$ とするとき, 次のような確率微 分方程式を満たす確率過程としてモデル化される $[6,7]$.

$$
d S_{t} / S_{t}=\mu d t+\sigma d W_{t}
$$

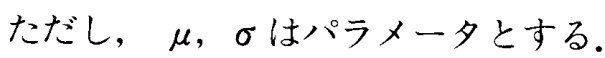

このとき, 株価変動 $d S_{t} / S_{t}$ は平均 $\mu d t$, 分散 $\sigma^{2}$ 
$d t$ の正規分布にしたがう.

しかし，本稿のはじめに，この正規分布という 仮定に疑念を呈したのであった。

\subsection{BDS 統計による検定}

それでは，必ずしも正規分布ではなく，独立で 同一分布にしたがうというように，これを一般化 した場合にはどうなのであろうか.この場合のモ デルは, 時間を離散的とし，株価の対数

$$
X_{t}=\ln S_{t}
$$

を用いて表現した場合には，次のように書くこと ができる。

$$
X_{t}=X_{t-1}+\mu+U_{t}
$$

ただし， $U_{t}$ は独立で同一分布にしたがう平均 0 で有限の分散をもつ確率変数とする.

このとき, 株価対数収益率 $\left(\ln S_{t}-\ln S_{t-1}\right)$ は, 独立で同一分布にしたがう確率変数，すなわち， IID (independent and identically distributed) で あるということになる，果なしてこれは実証され るのだろうか.

これを検定するのにBDS 統計と呼ばれる統計 量が開発されている。これは，デー夕系列 $\left\{x_{t}\right\}$ が IIDであるという帰無仮説を検定するもので，相 関積分を用いて Brock, Dechert, Scheinkman に より定式化されたものである $[30,31]$ (付録参照)。

Brock, Hsieh, LeBaron によると, S\&P 500 や 円ドル為替レートの対数収益率などを対象に BDS 統計による検定を行った結果，いずれも IID であるという帰無仮説が菓却されたという [31]. したがって，本稿のはじめに述べたように非正規 安定分布にしながう IID という仮説も否定され るわけである。

さらに，かなり短い期間のデータに対しても同 様の結果が得られているといj $[32]$ 。したがって， ある構造変化が生じるまでの期間はある分布にし たがう IID で，構造変化後の期間には別の分布に したがうIIDであるという様な形式のモデルで 定式化できる可能性も小さい。

\section{3 非線形確率過程}

確率過程 $\left\{X_{t}\right\}$ の中には， $X_{t}$ の間には自己相関は 全くないにもかかわらず， $X_{t}$ と $X_{t-1}$ とが明らかに 独立でないというようなものがある。たとえば， 次の $A R C H$ モデルは，そのような非線形確率過 程の代表的なものである。

$$
X_{t}=\left[a+b X_{t-1}^{2}\right]^{1 / 2} U_{t}
$$

ただし， $U_{t}$ : 正規分布 $N(0,1)$ にしたがう IID $a, b:$ 定数

BDS 統計による検定では, 当然このようなモデ ルによって生成されたデータが IID であるとい う帰無仮説は菓却される $[31,32]$.

したがって，株価変動や為替変動などの経済時 系列は,このような $\mathrm{ARCH}$ タイプのモデルや，そ れを含むもつと一般的な非線形な確率微分方程式 や非線形な確率差分方程式で規定される確率過程 にしたがっている可能性もある[32-34].

\section{4. 進化する徒雑系としての見方}

筆者の見るところ, 経済時系列がカオスである という確固たる証拠はまだ提出されていない。一 方で少なくとも低次元の典型的な決定論的力学系 から生ずるカオスではないという，どちらかとい うとネガティブな結果は得られている。その一方 で，独立で同一分布にしたがう全くのランダムな 系列でもないようである。

したがって, 高次元の決定論的な非線形力学系 にしたがっている可能性も残されているが，非線 形確率過程としてモデル化できる可能性も高い. いずれにしても，これらは現実的には識別するの が非常に難しい問題である.

他方で, 経済は, 気象, 政治, 価值観の変化, 科学技術の進歩など経済以外の多くから影響を受 けており，それだけで閉じてはいないという問題 もある。

さらに，現実の経済は常に技術革新や新商品開 発, 制度の改廃などにより常に変化し, 成長し, 進化する生きた系でもあることを忘れてはならな 
い。これは，そのダイナミクスをみた場合，常に 構造変化が問題になり, データの面からみた場合, 少しデータ期間を長くとると非定常となってしま うということにも現れている。

これらの観点からすると経済活動の結果が集約 された経済時系列が，単純な決定論的なモデルや 確率過程で記述されるような単純なものではなく, 生命の進化プロセスにも似た生きた複雑系として モデル化されるべきではないのかと思われる。こ のような問題意識による研究も，これまでいろい ろ行われてきているが[35], 決定的なものはまだ ないようである。

\section{5. おわりに}

以上述べてきた中にも幾つか出てきたが, 経済 データの分析に関しては，いろいろな結果が出さ れ見解が統一されていないケースが多い。その一 つの理由として, 経済自体が常に構造変化してい るため，計測時期により多様な顔を見せるのでは ないかという考え方がある $[36]$.

また一方で，経済の場合データ面の制約が多い ため，分析技術をその有効な範囲を超えて使って しまうケースもあるように思われる。この点に関 しては，筆者自身も必ずしも十分な自信がある訳 ではないが,これは研究の発展段階の上では避け て通れないことなのかも知れない.

いずれにしても，経済の持つ複雑さは何なのか, それはどのようにしたら捉えることが出来るのか は，未解決な問題として残されている．特に，こ こで取り上げたファイナンスにおける時系列デー 夕は，やっかいな代物ではあるが，興味の尽きな い研究対象である。

\section{参考 文 献}

[1]R. M. Goodwin: Chaotic Economic Dynamics, Oxford University Press(1990)。 [有賀裕二訳： カオス経済動学, 多賀出版 (1992)].

[2] J. Benhabib : Cycles and Chaos in Economic Equilibrium, Princeton University Press (1992).
[3] H. W. Lorenz : Nonlinear Dynamics and Chaotic Motion, Springer-Verlag(1989).

[4] 有賀鿆二: 経済とカオス, 合原一幸編：応用力オ ス, サイエンス社 (1994) 355-377所収.

５］西村和男, 矢野誠: 経済成長とカオス (連載1～連 載12)，経済セミナー，1993年4月号～1994年3月 号.

[6] J. Hull : Options, Futures, and Other Derivative Securities, Prentice Hall, Inc. (1989). [三菱 銀行商品開発室訳：フィナンシャルエンジニアリ ングー金融派生商品開発入門, 金融財政事情研究 会 (1989)]。

[7] 森村英典, 木島正明：ファイナンスのための確率 過程, 日科技連 (1991)。

[8] B. B. Madelbrot: The Fractal Geometry of Nature, W. H. Freeman and Company (1977). [広中平祐監訳：フラクタル幾何学, 日経サイエン ス社(1985)].

[9]岸本一男 : フラクタルに関連した2つの実証研究, 数理科学, 1994年4月号, 16-21.

[10］合原一幸：カオスーカオス理論の基礎と応用, サイエンス社(1990).

[11] E. Ott, T. Sauer and J. A. Yorke : Coping with Chaos, John Wiley \& Sons, Inc. (1994).

[12]F. Takens: Detecting strange attractors in turbulence. In D. Rand and L. -S. Young: Dynamical Systems and Turbulence, Springer (1981) $366-381$.

[13]合原一幸：ニューラルシステムに招けるカオス， 東京電機大学出版局 (1993)。

[14]M. Casdagli, S. Eubank, J. D. Farmer and J. Gibson: State space reconstruction in the presence of noise, Pysica D51(1991) 52-98.

[15]P. Grassberger and I. Procaccia : Measuring strangeness of strange attractors, Physica 9D (1983) 189-208.

[16]J. Scheinkman and B. LeBaron: Nonlinear dynamics and stock returns, J. Business, 62, 3(1989) 311-338.

[17]E. E. Peters : Chaos and Order in the Capital Markets, John Wiley \& Sons, Inc.(1991). [新田 功訳：カオスと資本市場, 白桃書房 (1994)].

[18]G. J. Deboeck: Trading on the Edge, John Wiley \& Sons, Inc. (1994) .

[19]D. Ruelle: Deterministic chaos: the science and the fiction, Proc. R. Soc. London, 
A427 (1990) 244-248.

[20]寺崎健, 池口徹, 合原一幸, 田中智：経済時系列 データの決定論的非線形ダイナミカル特性に関す る解析, 電子情報通信学会投稿中.

[21] 寺崎健 : 複雑性の科学と経済予測一株価変動の 非線形解析, KAST Report, 6, 2(1994) 4-7.

[22] M. Sano and Y. Sawada: Measurement of the Lyapunov spectrum from a chaotic time series, Phys. Rev. Lett., 55, 10(1985) 1082-1085.

[23] J.C. Vassilicos, A. Demos and F. Tata: No evidence of chaos but some evidence of multifractals in the foreign exchange and the stock markets. In A. J. Crilly, R. A. Earnshaw and H. Jones: Applications of Fractals and Chaos, Springer-Verlag(1993) 249-265.

[24]A.Wolf, J.B.Swift, H.L. Swinney and J.A. Vastano: Determining Lyapunov exponents from a time series, Physica 16D(1985) 285-317.

[25]G. Sugihara and R. M. May : Nonlinear forecasting as a way of distinguishing chaos from measurement error in time series, Nature, 344 (1990) 734-741.

[26]A. I. Mees: Tesselations and dynamical systems. In M. Casdagli and S. Eubank : Nonlinear Modeling and Forecasting, Addison-Wesley (1992) 3-24.

[27]T. P. Meyer and N. H. Packard : Local forecasting of high-dimensional chaotic dynamics. In M. Casdagli and S. Eubank : Nonlinear Modeling and Forecasting, Addison-Wesley(1992) 249-263.

[28]B.G. Malkiel : A Random Walk Down Wall Street, W.W. Norton \& Company, Inc. (1990). [井手正介訳：ウォール街のランダム・ウォーク， 日本経済新聞社(1993)]。

[29]S. E. Landsberg: The Armchair Economist, The Free Press (1993). [佐和隆光監訳：ランチ夕 イムの経済学, ダイヤモンド社(1995)].

[30]W. Brock, W. Dechert and J. Scheinkman : A test for independence based on the correlation dimension, University of Wisconsin, Madison, University of Houston, and University of Chicago (1987).

[31] W. A. Brock, D. A. Hsieh and B. LeBaron: Nonlinear Dynamics, Chaos, and Instability : Statistical Theory and Economic Evidence, The
MIT Press (1991).

[32]D. A. Hsieh : Chaos and nonlinear dynamics: Application to financial markets, The Journal of Finance, XLVI, 5(1991) 1839-1877.

[33]T. C. Mills: Nonlinear time series models in economics. In L. Oxley, D. A. R. George, C. J. Roberts and S. Sayer : Surveys in Econometrics, Blackwell (1995) 273-298.

[34] J. Creedy and V. L. Martin : Chaos and Nonlinear Models in Economics, Edward Elgar (1994).

[35]P. W. Anderson, K. J. Arrow and D. Pines:

The Economy as an Evolving Complex System, Addison-Wesley (1988).

[36]矢島邦昭：アセット・アロケーション戦略とリス ク管理一多様な価格変動特性のもとでの検討，第8 回応用時系列研究会報告資料 (1993) 7/1-14.

\section{付 録}

BDS 統計(BDS statistic)とは，1987年に Brock, Dechert, Scheinkmanにより考案された新しい統計 的な検定手法で $[30,31]$ ，あるデー夕系列 $\left\{x_{t}\right\}$ が同一の 確率分布から得られた独立なデー夕系列である，すな わち, IID (independent and identically distributed) であるという帰無仮説を検定するものである。これ は，

$$
x_{t}^{m}=\left(x_{t}, x_{t+1}, \cdots, x_{t+m-1}\right)
$$

とし，相関積分 (correlation integral)を

$$
\begin{aligned}
& C_{m, T}(\varepsilon)=2 \Sigma_{t<s} I_{\varepsilon}\left(x_{t}^{m}-x_{s}^{m}\right) / T_{m}\left(T_{m}-1\right) \\
& \text { ただし, } T \text { はデー夕総数で, } \\
& T_{m}=T-m+1 \\
& I_{\varepsilon}(x)=1 \quad(\|x\|<\varepsilon \text { のと }) \\
& =0 \quad(\|x\| \geqq \varepsilon \text { のとき })
\end{aligned}
$$

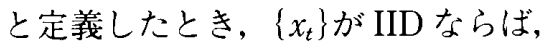

$$
C_{m, T}(\varepsilon)-C(\varepsilon)^{m}
$$

が漸近的に平均0の正規分布に収束するという事実に 基づいて作成されたもので，これを平均 0 ，分散1の正 規分布に収束するように正規化することによって定 義される。すなわち，

$$
B D S_{m, T}(\varepsilon)=T^{1 / 2}\left[C_{m, T}(\varepsilon)-C(\varepsilon)^{m}\right] / \sigma_{m, T}(\varepsilon) \text { (A.6) }
$$
ただし， 


$$
\begin{aligned}
& \sigma_{m, T}(\varepsilon)^{2}=4\left[K^{m}+2 \Sigma_{j=1}^{m-1} K^{m-j} C^{2 j}\right. \\
& \left.\quad+(m-1)^{2} C^{2 m}-m^{2} K C^{2 m-2}\right] \\
& \begin{aligned}
C= & C_{1, T}(\varepsilon) \\
K= & K_{T}(\varepsilon) \\
= & \Sigma_{t<s<r} h_{\varepsilon}\left(x_{t}^{m}, x_{s}^{m}, x_{r}^{m}\right)\left[6 / T_{m}\left(T_{m}-1\right)\left(T_{m}-2\right)\right]
\end{aligned}
\end{aligned}
$$

$$
h_{\varepsilon}(x, y, z)=\left[I_{\varepsilon}(x-y) I_{\varepsilon}(y-z)+I_{\varepsilon}(x-z) I_{\varepsilon}(z-y)\right.
$$$$
\left.+I_{\varepsilon}(y-x) I_{\varepsilon}(x-z)\right] / 3
$$

（A.7） [問い合わせ先]

(A.8) 厂240 横浜市保土ケ谷区神戸町134

(制野村総合研究所 技術研究開発部

寺崎 健

政：045-336-8447

[AXX : 045-336-1443

E-mail : t-terasaki@nri.co.jp

著者紹介

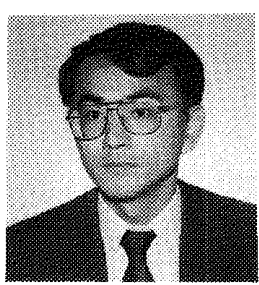

寺崎健ててらさきたし)

侏野村総合研究所 技術研究開発部 1977年 東京工業大学 大学院理工 学研究科情報科学専攻修士課程修了. 同年 (秼野村総合研究所入社. 経営計 画研究部, システムコンサルティン グ部などを経て，現在技術研究開発 部主任研究員. 非線形情報処理や知 的情報処理の金融・保険などを含む ビジネス領域全般への応用研究, 応 用システムの研究開発に従事. 